\title{
In vitro fermentation and prebiotic potential of selected extracts from seaweeds and mushrooms
}

Article

Accepted Version

Creative Commons: Attribution-Noncommercial-No Derivative Works 4.0

Rodrigues, D., Walton, G., Sousa, S., Rocha-Santos, T. A. P., Duarte, A. C., Freitas, A. C. and Gomes, A. M. P. (2016) In vitro fermentation and prebiotic potential of selected extracts from seaweeds and mushrooms. LWT Food Science and Technology, 73. pp. 131-139. ISSN 0023-6438 doi: https://doi.org/10.1016/j.Iwt.2016.06.004 Available at https://centaur.reading.ac.uk/65834/

It is advisable to refer to the publisher's version if you intend to cite from the work. See Guidance on citing.

To link to this article DOI: http://dx.doi.org/10.1016/j.Iwt.2016.06.004

Publisher: Elsevier

All outputs in CentAUR are protected by Intellectual Property Rights law, including copyright law. Copyright and IPR is retained by the creators or other copyright holders. Terms and conditions for use of this material are defined in the End User Agreement. 


\section{CentAUR}

Central Archive at the University of Reading

Reading's research outputs online 
1 In vitro fermentation and prebiotic potential of selected extracts from seaweeds and mushrooms

4 Dina Rodrigues ${ }^{a}$, Gemma Walton ${ }^{b}$, Sérgio Sousa ${ }^{c}$, Teresa A.P. Rocha-Santos ${ }^{a}$, $5 \quad$ Armando C. Duarte ${ }^{a}$, Ana C. Freitas ${ }^{a, d}$, Ana M.P. Gomes ${ }^{c}$

6

7 a CESAM - Centre for Environmental and Marine Studies \& Department of

8 Chemistry, University of Aveiro, Campus Universitário de Santiago, 3810-193

9 Aveiro, Portugal

10 b Department of Food and Nutritional Sciences, The University of Reading, RG6 11 6AP, UK

12 c Universidade Católica Portuguesa, CBQF - Centro de Biotecnologia e Química 13 Fina - Laboratório Associado, Escola Superior de Biotecnologia, Rua Arquiteto 14 Lobão Vital, Apartado 2511, 4202-401 Porto, Portugal

15 d ISEIT/Viseu, Instituto Piaget, Estrada do Alto do Gaio, Galifonge, 3515-776 16 Lordosa, Viseu, Portugal

* Corresponding author: Mailing address: CESAM \& Department of Chemistry, 19 University of Aveiro, 3810-193 Aveiro, Portugal. E-mail: dinarodrigues@ua.pt

21 This manuscript has been submitted for publication in LWT-Food Science and 22 Technology

23 It is not to be reproduced or cited without the written permission of the authors.

24 This article does not contain any studies with human or animal subjects.

25 The authors declare no conflict of interest. 
Abstract

27 Extracts with prebiotic activity or bioactive compounds from natural sources such as seaweeds or mushrooms, combining a broad spectrum of biological properties, may offer great potential for their use as functional ingredients enabling intestinal microbiota modulation. In this context, selected enzymatic extracts from

31 Sargassum muticum, Osmundea pinnatifida and Pholiota nameko were evaluated 32 in vitro. Faecal fermentations were conducted anaerobically under controlled 33 temperature and $\mathrm{pH}$ over $24 \mathrm{~h}$. Enzymatic extracts of $\mathrm{Ph}$. nameko and of $\mathrm{O}$. 34 pinnatifida at $1 \%(\mathrm{w} / \mathrm{v})$, lead to increases in Bifidobacterium spp. after $6 \mathrm{~h}$ of 35 fermentation in comparison to negative control, suggesting a stimulatory effect. 36 No significant changes over $24 \mathrm{~h}$ were observed of Lactobacillus spp. In 37 particular, the $\mathrm{Ph}$. nameko extract obtained with Flavourzyme not only stimulated 38 growth and/or activity of Bifidobacterium spp. but also led to a decrease of

39 Clostridium histolyticum group upon $24 \mathrm{~h}$, thus potentially benefiting colonic 40 health. Higher percentages of this extract (2 and $3 \%$ ) impaired a C. histolyticum 41 reduction confirming this selective action and prebiotic potential. Differences in 42 short chain fatty acids (SCFA) and lactic acid production between the four extracts 43 may indicate a potential relationship between their physico-chemical properties, 44 which differ in composition and structures, and modulation of gut bacterial 45 species.

46 Keywords: Seaweeds, mushrooms, enzymatic extracts, fluorescence in situ 47 hybridization (FISH), prebiotic activity 


\section{Introduction}

52 Edible seaweeds and mushrooms are an excellent source of bioactive 53 compounds (Pádua, Rocha, Gargiulo, \& Ramos, 2015; Ruthes, Smiderle, \& 54 lacomini, 2016) and therefore research into the biological potential of enzymatic 55 extracts of seaweeds S. muticum and $O$. pinnatifida and of mushroom $\mathrm{Ph}$. 56 nameko to be explored within the functional food perspective, were selected for in 57 vitro fermentation study to consolidate their prebiotic potential (Rodrigues et al., 58 2015,2016).

59 Prebiotics are defined as substrates that improve the host health by selectively 60 stimulating the growth and/or metabolic activity of one or a limited number of 61 beneficial bacteria in the colon (Roberfroid et al., 2010). The potential prebiotic 62 effect of the selected extracts has been evaluated by comparison with 63 fructoligosaccharides (FOS), the gold standard in comparison studies, using pure 64 cultures (Lactobacillus acidophilus La5; Bifidobacterium animalis BB12) 65 (Rodrigues et al., 2015,2016). The human gastrointestinal tract represents a 66 complex ecosystem where the available nutrients and the diverse microbiota will 67 influence changes within the community (Roberfroid et al., 2010). Hence, to assess the possible importance that colonic catabolism of these extracts may have on human gut microbiota, in vitro batch culture fermentation experiments conducted with faecal inoculum from healthy volunteers, are in order to observe

71 changes in the main bacterial groups present within (Eid et al., 2014; Sánchez72 Patán et al., 2012). The human colon is considered the most metabolically active site in the human body with over 1000 species of microorganisms reaching up to

$7410^{12}-10^{13}$ bacteria per gram dry weight (Roberfroid et al., 2010). To study this 75 diverse community $\mathrm{pH}$ controlled, anaerobic faecal batch cultures enable 
assessment of the fermentability of substrates in the intestinal lumen, whilst

77 simulating the conditions in the human distal colon (Bergillos-Meca, Costabile,

78 Walton, Moreno-Montoro, Ruiz-Bravo, \& Ruiz-López, 2015). A growing body of evidence suggests that the gut microbiota impacts on a wide range of host metabolic pathways, barrier function and immune modulatory function influencing the prevention and risk of a wide range of diseases, including inflammatory bowel disease, diarrhoea and colorectal cancer. Much of this impact is mediated through diet and the consumption of specific health-related foods, justifying the constant need to modulate diet or identify compounds that can positively modify the gut microbiota (Gibson, Scott, Rastall, \& Tuohy, 2010).

Research has been focused on 'prebiotics', and in particular the ability of certain types of dietary fibre, especially indigestible oligosaccharides, to stimulate the lactobacilli while retarding the development of $C$. histolyticum, leading to a concomitant positive effect on colonic health (Gibson et al., 2010; Aida, Shuhaimi,

91 Yazid \& Maaruf, 2009). Better understanding of the benefits of prebiotics has urged a need to search for and develop new and alternative sources of prebiotics. According to Zaporozhets et al. (2014), the prebiotic activity of extracts or of polysaccharides from marine seaweeds, combined with a broad spectrum of biological properties, evidences great potential for their use as functional nutrition ingredients enabling modulation of intestinal microbiota and of gastrointestinal tract (GIT) inflammation as well as normalization of the immune system. Therefore the main objective in this study was to evaluate the potential of the digested (closely simulating physiological conditions) seaweed and mushroom extracts containing different polysaccharide and oligosaccharide structures on gut 
101 microbial ecology. To our best knowledge there are no studies regarding the impact of water-based enzyme-assisted extracts for seaweeds $S$. muticum, $O$. pinnatifida or mushroom $P h$. nameko on gut microbial ecology confirm and consolidate the biological potential of these selected extracts, for their application as functional food and bioactive ingredient sources.

\section{Material and methods}

2.1. Selected seaweeds and mushrooms extracts

In this study water-based enzyme-assisted extracts from two seaweeds and one mushroom were selected following demonstration of potential prebiotic effect with pure cultures (Rodrigues et al., 2015,2016). Selected extracts included extracts of S. muticum obtained with Alcalase, O. pinnatifida obtained with Viscozyme and Ph. nameko obtained with Cellulase and with Flavourzyme. For each extract, $1 \mathrm{~g}$ of dried mushroom or $2 \mathrm{~g}$ of dry seaweed was dispersed in $50 \mathrm{~mL}$ of deionised water and incubated in an agitated water bath for $10 \mathrm{~min}$. After adjusting $\mathrm{pH}$ to specific enzyme optimum conditions (Alcalase: $\mathrm{pH}=8$ - $50 \stackrel{\circ}{\circ}$; Flavourzyme: $\mathrm{pH}=7.0$ - $50^{\circ} \mathrm{C}$; Cellulase: $\mathrm{pH}=4.5-50^{\circ} \mathrm{C}$; Viscozyme ${ }^{\circledR} \mathrm{L}: \mathrm{pH}=4.5-50^{\circ} \mathrm{C}$; All enzymes were obtained from Sigma-Aldrich), $100 \mathrm{mg}$ of enzyme was added and incubated for enzymatic hydrolysis for $24 \mathrm{~h}$ at $50 \stackrel{\circ}{\circ}$. The enzymatic reaction was stopped by heating the sample at $90-100 \stackrel{\circ}{ } \mathrm{C}$ for 10 min followed by immediate cooling in an ice bath. The $\mathrm{pH}$ of enzymatic extracts was adjusted to $\mathrm{pH} 7.0$ with

$1221 \mathrm{M} \mathrm{HCl}$ and/or $\mathrm{NaOH}$ and then centrifuged, filtered and freeze-dried according to 123 Rodrigues et al. $(2015,2016)$. 
126 Samples of the selected extracts were submitted to three consecutive steps: 1)

127 Simulated gastrointestinal digestion; 2) Faecal batch-culture fermentation and, 3)

128 Bacterial enumeration using FISH.

130 To simulate the digestion of the selected seaweed and mushroom extracts 131 through the gastrointestinal tract and therefore evaluate the main effects of the digested extracts on human microbiota, samples were treated according to Mills 133 et al. (2008), with slight alterations. Water $(25 \mathrm{~mL})$ was added to $10 \mathrm{~g}$ of lyophilized extract, and the mixture was stomached (Seward, UK) for 5 min using 135200 paddle-beats per min. The extract solution was then mixed with $\alpha$-amylase 136 (A4551, Sigma; $3.33 \mathrm{mg})$ in $\mathrm{CaCl}_{2}(0.001 \mathrm{M}, \mathrm{pH} 7.0 ; 1.04 \mathrm{~mL})$ and incubated at 37 $137{ }^{\circ} \mathrm{C}$ for $30 \mathrm{~min}$ and at $130 \mathrm{rpm}$ in a shaker. Afterwards, the $\mathrm{pH}$ was decreased to 2.0 with $6 \mathrm{M} \mathrm{HCl}$ and pepsin (P 7000, Sigma; $0.45 \mathrm{~g})$ dissolved in $\mathrm{HCl}(0.1 \mathrm{M}$; $4.16 \mathrm{ml}$ ) was added. The sample was incubated at $37^{\circ} \mathrm{C}$ for $2 \mathrm{~h}$ and at $130 \mathrm{rpm}$ in 140 a shaker. After this period, the $\mathrm{pH}$ was increased to 7 with $6 \mathrm{M} \mathrm{NaOH}$, and pancreatin ( $\mathrm{P}$ 8096, Sigma; $0.93 \mathrm{~g}$ ) and bile (B 8631, Sigma; $0.58 \mathrm{~g}$ ) in $\mathrm{NaHCO}_{3}$ (0.5 M; $20.8 \mathrm{~mL})$ were added. The extract solution was then incubated at $37{ }^{\circ} \mathrm{C}$ and at $45 \mathrm{rpm}$ in a shaker for $3 \mathrm{~h}$ and afterwards transferred to $1 \mathrm{kDa}$ molecular weight cut-off regenerated cellulose dialysis tubing (Spectra/Porß 6, Spectrum Europe, Netherlands) and dialyzed against $\mathrm{NaCl} 0.01 \mathrm{M}$ at $5^{\circ} \mathrm{C}$, to remove low molecular mass digestion products. After $15 \mathrm{~h}$ the $\mathrm{NaCl}$ dialysis fluid was changed and dialysis continued for an additional $2 \mathrm{~h}$. Afterwards the digested samples were frozen at $-80^{\circ} \mathrm{C}$ and lyophilized in a freeze dryer (Armfield SB4 model,

149 Ringwood, UK). All chemicals were purchased from Sigma (St Louis, USA).

$150 \quad$ 2.2.2. Faecal batch-culture fermentation 
151 Three independent fermentation experiments were carried out. Faecal samples

152 were obtained fresh at the premises of the Department of Food and Nutritional

153 Sciences from 3 apparently healthy adult volunteers who ingested a normal diet,

154 had not ingested any antibiotics for at least 6 months and were not regular

155 consumers of pre or probiotics. Samples were collected into sterile vials and kept

156 in an anaerobic cabinet and used within 30 min of collection. A 1/10 (w/w) dilution

157 in phosphate buffer saline (PBS) was prepared and homogenized using a

158 stomacher (Serward, Worthing, UK) for 2 min at 460 paddle-beats per min.

159 Sterile stirred batch culture fermentation vessels (50 mL working volume) were set

160 up and aseptically filled with $45 \mathrm{~mL}$ sterile, pre-reduced, basal medium [peptone 161 water $2 \mathrm{~g} / \mathrm{L}$, yeast extract $2 \mathrm{~g} / \mathrm{L}, \mathrm{NaCl} 0.1 \mathrm{~g} / \mathrm{L}, \mathrm{K}_{2} \mathrm{HPO}_{4} 0.04 \mathrm{~g} / \mathrm{L}, \mathrm{KH}_{2} \mathrm{PO}_{4} 0.04 \mathrm{~g} / \mathrm{L}$, 162 $\mathrm{MgSO}_{4} .7 \mathrm{H} 2 \mathrm{O} 0.01 \mathrm{~g} / \mathrm{L}, \mathrm{CaCl}_{2} .6 \mathrm{H}_{2} \mathrm{O} 0.01 \mathrm{~g} / \mathrm{L}, \mathrm{NaHCO}_{3} 2 \mathrm{~g} / \mathrm{L}$, Tween $802 \mathrm{~mL} / \mathrm{L}$ 163 (BDH, Poole, UK), Hemin 0.05 g/L, vitamin K1 $10 \mu \mathrm{L} / \mathrm{L}$, L-cysteine-HCl $0.5 \mathrm{~g} / \mathrm{L}$, 164 bile salts $0.5 \mathrm{~g} / \mathrm{L}, \mathrm{pH} 7.0$ ] and gassed overnight with $\mathrm{O}_{2}$-free $\mathrm{N}_{2}(15 \mathrm{~mL} / \mathrm{min})$ with 165 constant agitation. All media and chemicals were purchased from Oxoid 166 (Basingstoke, UK) and Sigma (St Louis, USA). The temperature was kept at $37^{\circ} \mathrm{C}$ and $\mathrm{pH}$ was controlled between 6.7 and 6.9 using an automated $\mathrm{pH}$ controller 168 (Fermac 260, Electrolab, Tewkesbury, UK), which added acid or alkali $(0.5 \mathrm{M} \mathrm{HCl}$ and $0.5 \mathrm{M} \mathrm{NaOH}$ ) in order to mimic conditions that resemble the distal region of

170 the human large intestine (Sánchez-Patán et al., 2012).

171 Six stirred pH-controlled batch fermenters were run in parallel. The different 172 digested extracts $(1 \% \mathrm{w} / \mathrm{v})$ were aseptically added to four vessels, the other two 173 vessels were used as controls. For the positive control vessel $1 \%(\mathrm{w} / \mathrm{v})$ of FOS 174 (95\% oligofructose, $0.5 \mathrm{kDa}$ dextran with 25\% $\alpha-1,2$ branching, $1 \mathrm{kDa}$ dextran with $17532 \% \alpha-1,2$ branching; Orafti $B_{P}$ P5, Oreye, Belgium) was used. To the negative 
control vessel no source of carbon was added. The experiment was performed in triplicate, using one faecal sample given by a different donor for each run of six batch fermenters. Each vessel, with $45 \mathrm{~mL}$ sterile medium and digested extract, was inoculated with $5 \mathrm{~mL}$ of fresh faecal slurry $(1 / 10 \mathrm{w} / \mathrm{w})$. The batch cultures were run under anaerobic conditions for a period of $24 \mathrm{~h}$, during which $5 \mathrm{~mL}$ samples were collected from each vessel at $0,6,12$ and $24 \mathrm{~h}$ for FISH and analysis of lactic acid and short chain fatty acids (SCFA). For this latter analysis, samples were stored at $-70 \stackrel{\circ}{ } \mathrm{C}$ until required.

In order to assess the effect of the addition of 2 and $3 \%$ of digested extracts of $O$. pinnatifida obtained with Viscozyme and of Ph. nameko obtained with Flavourzyme, faecal batch-culture fermentations were repeated, in triplicate, under similar conditions but non-pH controlled and at lower volumes $(10 \mathrm{~mL})$ and for a period of $12 \mathrm{~h}$.

2.2.3. Bacterial enumeration using FISH.

To assess differences in bacterial composition, FISH was used with oligonucleotide probes designed to target specific diagnostic regions of 16S rRNA based on the method described by Daims, Stoecker, \& Wagner (2005). A total of 6 different probes commercially synthesized and 5'-labelled with the fluorescent dye (Sigma Aldrich, St Louis, USA) were used in addition to an overall stain with 4,6-diamidino-2-phenylindole (DAPI), which measures all cells by staining DNA (Harmsen, Wildeboer-Veloo, Grijpstra, Knol, Degener, \& Welling, 2000a; Harmsen et al., 2000b).

Samples $(375 \mu \mathrm{L})$ obtained from each vessel and sampling time were fixed for a minimum of $4 \mathrm{~h}(4 \stackrel{\circ}{\circ})$ in $1125 \mu \mathrm{L} 4 \%(\mathrm{w} / \mathrm{v})$ paraformaldehyde. Fixed cells were centrifuged at 13,000 $\mathrm{g}$ for $5 \mathrm{~min}$ and washed twice in $1 \mathrm{~mL}$ filtered sterilized PBS. 
201 The washed cells were re-suspended in $150 \mu \mathrm{L}$ filtered PBS and stored in $150 \mu \mathrm{l}$ ethanol $(99 \%)$ at $-20{ }^{\circ} \mathrm{C}$ until further processing. Samples were then diluted in a suitable volume of PBS in order to obtain countable fluorescent cells in each field of view and $20 \mu$ of the above solution was added to each well of a 6 well PTFE/poly-L-lysine coated slide (Tekdon Inc., Myakka City, USA). The samples were dried for 15 min in a drying chamber $\left(46^{\circ} \mathrm{C}\right)$.

To permeabilize cells for use with probes Bif164 and Lab 158 (Table 1), samples were treated with $20 \mu \mathrm{L}$ of lysozyme at room temperature for 15 min before being washed briefly in water. Slides were dehydrated, using an alcohol series $(50,80$ and $96 \%(\mathrm{v} / \mathrm{v})$ ethanol) for $3 \mathrm{~min}$ in each solution. Slides were returned to the drying oven for 2 min to evaporate excess ethanol before adding the hybridization mixture to each well $[(0.9 \mathrm{M} \mathrm{NaCl}, 0.02 \mathrm{M}$ Tris/ $\mathrm{HCl}(\mathrm{pH} 8.0), 0.01 \%$ sodium dodecyl sulphate and $4.55 \mathrm{ng} / \mathrm{mL}$ probe]. For probes EUB338 I-II-III, the hybridization mixture contained formamide $[(0.9 \mathrm{M} \mathrm{NaCl}, 0.02 \mathrm{M}$ Tris/ $\mathrm{HCl}(\mathrm{pH} 8.0)$, $35 \%$ formamide, $0.01 \%$ sodium dodecyl sulphate and $4.55 \mathrm{ng} / \mathrm{mL}$ probe]. Hybridization occurred for $4 \mathrm{~h}$ in a microarray hybridization incubator (GrantBoekel, Cambridge, UK). After hybridization, slides were washed in $40 \mathrm{~mL}$ washing buffer $[0.9 \mathrm{M} \mathrm{NaCl}$ and $0.02 \mathrm{M} \mathrm{Tris} / \mathrm{HCl}(\mathrm{pH} 8.0)]$, and $0.005 \mathrm{M}$ ethylenediaminetetraacetic acid for the EUB338 I-II-III probes with $20 \mu$ l nucleic acid stain 4', 6-diamidino-2- phenylindole (DAPI; $50 \mathrm{ng} / \mu \mathrm{L}$ ) for $15 \mathrm{~min}$. They were then dipped in cold water for a few seconds and dried with compressed air. Five 222 microlitres of polyvinyl alcohol mounting medium with 1,4diazabicyclo(2,2,2)octane (DABCO) was added onto each well and a cover slip was placed on each slide (20 mm, thickness No 1, VWR, Lutterworth, UK). Slides were examined by epifluorescence microscopy (Eclipse 400, Nikon, Surrey, UK) 
226 using the Fluor 100 lens. For each well, 15 fields with a maximum of 300 positive 227 cells were counted.

228 2.2.4. Lactic acid and SCFA analysis

229 Samples were collected from each batch culture at each sampling point $(0,6,12$ 230 and $24 \mathrm{~h}$ ) and frozen at $-70^{\circ} \mathrm{C}$ until required. Samples were assessed for lactic 231 acid and SCFA (acetic, propionic, butyric, isobutyric and isovaleric acids) using an 232 HPLC apparatus from Merck LaChrom (Fullerton CA, USA), in a single run, based 233 on calibration curves previously prepared with appropriate chromatographic 234 standards; an Aminex HPX-87X cation exchange column from BioRad (Richmond 235 CA, USA) was used for separation; the eluant was pumped at $0.8 \mathrm{~mL} / \mathrm{min}$ and 236 consisted of $13 \mathrm{mM} \mathrm{H}_{2} \mathrm{SO}_{4}$ (Merck); and detection was by UV absorbance at 220 $\mathrm{nm}$. Prior to analysis, samples were defrosted, centrifuged $(13,000 \mathrm{~g}$ for $10 \mathrm{~min}$ at $4 \stackrel{\circ}{-}$ ) and filtered through a $0.22-\mu m$ membrane filter (Millipore, USA) to remove all particulate matter.

\subsection{Statistical Analysis}

A paired Student's $t$ test was used to test for significant differences in the bacterial 242 group populations between extracts and controls as well as for time in vitro 243 fermentation experiments by human gut microbiota. All data of bacterial 244 populations $\left(\log _{10}\right.$ cell $/ \mathrm{mL}$ ) are expressed as average of three replicates (donors) 245 plus or minus standard deviation, justifying the high variability reported in several 246 cases.

\section{Results and discussion}

3.1. Modulation of intestinal microbiota by seaweed and mushroom digested 250 extracts. 
251 Assessment of the prebiotic potential of bioactive compounds or extracts by in 252 vitro fermentation with human faecal microbiota provides a cost-effective and 253 rapid alternative to assess the fermentation and modulation capacity of different 254 substrates on a laboratory scale comparative basis (Gullon, Gullon, Tavaria, 255 Pintado, Gomes, Alonso, \& Parajo, 2014). It is important to note that before 256 performance of in vitro fermentations care was taken to submit each extract to 257 simulated gastrointestinal digestion because resistance to gastric acidity and hydrolysis by mammalian enzymes are limiting factors that have to be assured in order to enable the substrate to reach the colon and be fermented by intestinal microbiota, meeting the pre-requisite for a prebiotic effect or gut modulation effect. According to Gibson et al. (2010) any dietary material that is non-digestible and enters the large intestine is a candidate prebiotic. The few studies that have evaluated the prebiotic potential of seaweed polysaccharides using in vitro fermentation (laminarin and low molecular weight polysaccharides from agar and alginate) did not undergo previous gastrointestinal digestion, hindering analysis of true effectiveness of intact compounds (Devillé, Gharbi, Dandrifosse, \& Peulen, 2007; Ramnani et al., 2012). During the experimental time course (0, 6, 12 and 24 h) of the in vitro fermentation of the digested seaweed and mushroom extracts at $1 \%(\mathrm{w} / \mathrm{v})$ changes in the different bacterial populations and accumulation of lactic acid and SCFA (acetic, propionic, butyric acids) were assessed. For comparative

271 purposes, the same experimental strategy was used with the well-established 272 prebiotic FOS (positive control) and with medium without carbon source present 273 (negative control) (Fig. 1).

274 FISH was used to monitor the modifications among populations of selected 275 bacterial species caused by the different digested S. muticum, O. pinnatifida and 
276 Ph. nameko enzymatic extracts added at 1\%, on a comparative basis. Depending

277 on the bacterial group different effects were observed. Both enzymatic extracts of

278 Ph. nameko and that of seaweed O. pinnatifida obtained with Viscozyme lead to 279 overall increases in Bifidobacterium spp. populations as compared to the negative 280 control between 6 and $24 \mathrm{~h}$ of fermentation, confirming a stimulatory effect (Fig. 281 1.a). Highest shift was observed for medium containing Ph. nameko extract 282 obtained with Flavourzyme raising bifidobacterial counts from $8.06 \pm 0.66 \log _{10}$ $283 \mathrm{cell} / \mathrm{mL}$ at $0 \mathrm{~h}$ to $8.49 \pm 0.06 \log _{10} \mathrm{cell} / \mathrm{mL}$ at $24 \mathrm{~h}(p=0.391)$ in comparison to the 284 negative control at $24 \mathrm{~h}(p=0.021)$. Evidence for a potential prebiotic effect for 285 pure culture of $B$. animalis BB12 was observed for undigested Ph. nameko 286 enzymatic extracts (Rodrigues et al., 2016). The positive control FOS, did 287 however induce a higher increase in bifidobacterial numbers after $24 \mathrm{~h}$ of 288 fermentation; from $8.04 \pm 0.47$ at $0 \mathrm{~h}$ to $8.98 \pm 0.13$ at $24 \mathrm{~h}(p=0.017)$. Indeed a twofold higher increase was observed for FOS $\left(0.94 \log _{10}\right)$ when compared to $P h$. nameko extract obtained with Flavourzyme $\left(0.43 \log _{10}\right)$.

291 No significant lactobacilli populations changes were observed over the $24 \mathrm{~h}$ in 292 comparison to the negative control for any of the four extracts tested at $1 \%$ except 293 for FOS (Fig. 1.b). These results contrast with those reported in previous studies 294 obtained with pure cultures of L. acidophilus La-5; significant higher values $295(p<0.05)$ of viable cells were observed for the majority of culture media enriched with seaweed water-based extracts (Rodrigues et al., 2015) and with Ph. nameko 297 extracts (Rodrigues et al., 2016) after $24 \mathrm{~h}$ of incubation in comparison to growth 298 in media with glucose or FOS. Ramnani et al. (2012) also reported absence of 299 effect on gut lactobacilli populations by low molecular weight polysaccharides 300 from agar and alginate seaweeds. 
301 The stimulation of growth and/or activity of beneficial gut bacteria such as Bifidobacterium by the digested extract of Ph. nameko obtained with Flavourzyme was associated with a decrease in numbers of the $C$. histolyticum after $24 \mathrm{~h}$ fermentation, in comparison to the negative control (Fig. 1.e). Such a change can be considered a concomitant positive effect on colonic health (Gibson et al., 2010; Aida et al., 2009). Furthermore, it can also be highlighted that although not statistically significant, the positive control FOS was associated with an increased number of cells of $C$. histolyticum after 12 and $24 \mathrm{~h}$ in comparison to the negative control (Fig. 1.e); in contrast, decreased numbers of $C$. histolyticum were observed in particular for the extracts of $O$. pinnatifida, S. muticum and $P h$. nameko obtained with Flavourzyme. Although there is a clear difference in response between FOS and studied extracts, it must be mentioned that some seems to be the less promising of the tested extracts considering the absence of a positive shift for both the Bifidobacterium and lactobacilli groups and their positive influence on the Clostridium groups at 6 and $12 \mathrm{~h}$ (Fig 1.a,b and e).

322 The four digested extracts at $1 \%$ led to similar increases in numbers of total bacteria after $24 \mathrm{~h}$ fermentation in comparison to the negative control, which $\mathrm{y}$ reported a slight reduction in numbers by $24 \mathrm{~h}$ (Fig. 1.f). Furthermore, the four 
326 decrease in numbers of the Clostridium cocoides/E. rectale group (Fig. 1.d), which

327 is a major anaerobic population in the human gut. Statistically significant

328 decreases $(p<0.05)$ were observed for $S$. muticum extract alongside both negative

329 and positive controls for C. cocoides/E. rectale.

330 Bacteroides/Prevotella population (Bacteroides group) showed an increase over 331 the $24 \mathrm{~h}$ of fermentation for all the four digested extracts, being statistically 332 significant for the $S$. muticum extract and for both extracts of Ph. nameko in 333 comparison to the negative control or to the positive FOS which revealed no 334 significant shift in numbers over the $24 \mathrm{~h}$ fermentation period (Fig. 1c). It is known 335 that these genera vary greatly with the nature of the diet and while studies have 336 revealed increased proportions of Bacteroides in vegetarians (Matijasic, 337 Obermajer, Lipoglavsek, Grabnar, Avgustin, \& Rogelj, 2014), or upon ingestion of resistant starch type 4 (Martinez, Kim, Duffy, Schlegel, and Walter, 2010), further studies have detected no alterations in Bacteroides upon ingestion of formula diet containing FOS and pea fibre (Benus et al., 2010) or upon blueberry drink consumption (Vendrame, Guglielmetti, Riso, Arioli, Klimis-Zacas, \& Porrini, 2011). 342 In contrast, in a study by Vulevic, Juric, Tzortzis, \& Gibson (2013), galactooligosaccharide consumption by overweight adults led to a reduction in the Bacteroides population. Although Bacteroides/Prevotella populations increased with the addition of the digested extracts to the medium it is important to correlate shift in population with the production of SCFA. Bacteroides and Prevotella genera are organisms capable of using a very wide range of substrates and are major producers of propionic acid. As may be seen from data listed in Table 2 and discussed further, propionic production is significant by $24 \mathrm{~h}$ fermentation, and of the same order of magnitude, for the positive control FOS and for both the Ph. 
351 nameko extracts, yet branched-chain fatty acids are reduced, which is concurrent 352 with a decrease in protein fermentation and of positive influence as far as 353 Bacteroides modulation is concerned.

354 In order to observe if increasing concentrations of the digested enzymatic 355 seaweeds and mushroom extracts would have a higher impact on gut microbiota 356 modulation, similar in vitro fermentations were repeated with 2 and $3 \%(\mathrm{w} / \mathrm{v})$ of extracts of $O$. pinnatifida obtained with Viscozyme and of $P h$. nameko obtained with Flavourzyme. The selection of these two extracts was based on the best prebiotic potential selectivity effect demonstrated within each group of extracts, seaweeds and mushroom. The respective results are displayed in Figure 2. Interesting results were obtained for Bifidobacterium spp., Lactobacillus spp. and C. histolyticum group (Fig. 2.a, 2.b and 2.e), respectively; - an increase in the concentration of the digested extracts did not bring about a higher impact on Bifidobacterium spp. abundance and increases in population numbers were similar between digested extracts and the positive control FOS in comparison to the negative control which registered no alteration over $12 \mathrm{~h}$ fermentation; abundance in the lactobacilli group was significantly increased with 2 and 3\% digested extracts in comparison to the digested extracts at $1 \%$ fermentation (Fig. 1.b) where no significant increases had been observed for the extracts; - higher increases in lactobacilli populations, although not statistically significant $(p>0.05)$, were observed between 0 and 6 h for both concentrations of $P h$. nameko extracts 372 than with FOS at $2 \%$ and at $12 \mathrm{~h}$ of fermentation similar numbers of cells were 373 observed for both $P h$. nameko extracts and these were higher than those 374 obtained with FOS $2 \%$ and with the negative control; - although the experiments with 2 and 3\% Ph. nameko extract started with the lowest level of C. histolyticum 
376 in the faecal inocula these extracts brought about the only statistical significant

377 decreases of C. histolyticum by $12 \mathrm{~h}(\mathrm{p}=0.0003$ for $2 \%$ and $\mathrm{p}=0.028$ for $3 \%$,

378 respectively) in comparison to $0 \mathrm{~h}$ and in comparison to FOS ( $p>0.05)$ and

379 negative control $(p>0.05)$. Numbers of $C$. histolyticum continued to diminish with

380 higher percentages of $P h$. nameko Flavourzyme extracts (in comparison to $1 \%$

381 extract) confirms their selectivity properties and prebiotic potential, although this

382 result could be a consequence of the lower $\mathrm{pH}$ (non-pH controlled experiment)

383 inhibitory effect on the microbial group, must not be overlooked. At higher

384 percentages cross-feeding may become more predominant and selectivity could

385 in fact be lost, yet this is not the case since $C$. histolyticum showed no proliferation

386 and decreased in numbers.

$387 \quad 3.2$ Lactic acid and SCFA production

388 Lactic acid and SCFA, the main products arising from the microbial fermentation 389 of carbohydrates, can provide energy to the colonic epithelium, modulate 390 cholesterol and lipid metabolism, suppress pathogenic intestinal bacteria and 391 modulate the immune system (Salazar, Prieto, Leal, Mayo, Bada-Gancedo, \& 392 Madiedo, 2009). Furthermore, they act as electron sinks of anaerobic respiration 393 in the gut and decrease the intestinal $\mathrm{pH}$, thus enhancing the bioavailability of 394 minerals such as calcium and magnesium (Gullon et al., 2014). The concentration 395 of acetic, propionic, butyric, isobutyric and isovaleric acids as well as lactic acid 396 produced during $24 \mathrm{~h}$ fermentation of the different extracts added at $1 \%$ is shown 397 in Table 2. Significant differences were found between donors with respect to the 398 levels of the different SCFA, in particular with acetic and butyric acids. In some 399 cases the SCFA were detected in only one donor, particularly for propionic, 
400 butyric and branched-chain fatty acids. It is estimated that $90 \%$ of SCFA are 401 absorbed and therefore low levels may be found in faeces

402 , SCFA production in the negative control was the lowest ( $14.3 \mathrm{mM}$ by $24 \mathrm{~h}$ ) in comparison with the media containing either the seaweed or the mushroom extracts. The lack of a carbohydrate may ascribe SCFA production in the negative control to protein degradation by putrefactive bacteria (Gullon et al., 2014) or to residual undigestive components within the faeces. The total SCFA concentrations achieved were highest for medium containing the positive control FOS (75.1 mM by $24 \mathrm{~h}$ ), followed by medium added with the Ph. nameko extracts (50.9 and $50.5 \mathrm{mM}$ by $24 \mathrm{~h}$ for Ph. nameko Flavourzyme extract and Ph. nameko

Viscozyme extract (26.7 mM) and S. muticum Alcalase extract (20.0 mM by $24 \mathrm{~h})$.

412 These observations correlate well with the observed modulation by the associated extracts of SCFA producer bifidobacterial and lactobacilli bacterial populations

414 discussed in the previous section. Importantly, most of the SCFA production 415 occurred during the first $12 \mathrm{~h}$ of fermentation. Acetic and propionic acids were the main SCFA produced in all media containing any of the four extracts or FOS.

417 Highest values for both acetic and propionic acids were observed in media containing FOS, yet importantly concentrations were also produced in media containing either of the $P h$. nameko extracts. Propionic acid concentrations were 420 highest for media containing FOS or the Ph. nameko extract obtained with 421 Flavourzyme. These concentrations may be related to the high numbers of 422 Bacteroides present or to the presence of specific compounds in the extracts. 423 Broekaert, Courtin, Verbeke, Van de Wiele, Verstraete, \& Delcour (2011), 424 associated propionic acid production with the side chains found in 
425 xilooligosaccharides. The acetic-to-propionic ratio increased along fermentation 426 for all substrates except for the Ph. nameko Flavourzyme extract, which 427 registered an effective decrease between 12 and $24 \mathrm{~h}$ ( 1.1 to 0.8 ). Low acetic-to428 propionic ratios have been proposed as a positive marker for a hypolipidemic 429 effect consequence of cholesterol biosynthesis inhibition (Salazar, Gueimonde, 430 Hernández-Barranco, Ruas- Madiedo, \& de los Reyes-Gavilán, 2008). All tested extracts led to the production of low levels of butyric acid by $24 \mathrm{~h}$ fermentation in 432 comparison to the positive control FOS. In general, levels of butyric acid were 433 either similar to those obtained by FOS, as is the case of $O$. pinnatifida extract 434 (average values of $5.9 \mathrm{mM}$ against $6.6 \mathrm{mM} \mathrm{FOS}$ ) or ca. two-fold lower as for $P h$. 435 nameko extracts (average values of 3.0 and $2.3 \mathrm{mM}$ ); values reported for FOS were however quite moderate in comparison to values reported for other studies 437 (for example 12-24 mM in Gullon et al., 2014) albeit a high variability between donors must be highlighted in this latter case. Related results were reported by Benus et al. (2010) who showed that butyric acid was reduced following the fibre440 supplemented diet (FOS and pea fibre).

441 Concentrations of the branched chain fatty acids, isobutyric and isovaleric acids were either below detection limit or, in many cases, were detected in only one donor.

Lactic acid production was highest when FOS was used as a substrate correlating well with the predominant Bifidobacterium/Lactobacillus populations. Lactic acid was also produced in the media containing the tested substrates during the first 6 $447 \mathrm{~h}$ of fermentation, in contrast to medium with FOS which achieved maximum lactic acid production by $12 \mathrm{~h}$ fermentation. Thereafter, lactic acid was consumed independently of the substrate in question. Consumption rate was highest in 
450 media containing FOS. This observation may eventually suggest a cross-feeding

451 mechanism (Gullon et al., 2014).

452 The differences observed in SCFA and lactic acid production for the four 453 substrates tested tend to indicate that a relationship may exist between physico454 chemical properties of extracts and modulation of individual bacterial species and 455 SCFA production in the gut. The four extracts tested displayed different 456 composition (for example, higher content of sugars was observed in extracts 457 obtained with Viscozyme and Cellulase) and structures (less sulphated 458 polysaccharides in $O$. pinnatifida extract or presence of $\alpha$ and $\beta$-glycosidic 459 structures such as glucans and glucan-protein complexes in both $\mathrm{Ph}$. nameko 460 extracts) some of which may be more accessible for use (Rodrigues et al., $4612015,2016)$. The different enzymatic treatments on the different seaweed or 462 mushroom sources lead to the release of different oligomer residues from the 463 structural and storage polysaccharides making these susceptible to degradation. 464 Similarly, Ramnani et al. (2012) showed that low molecular weight extracts 465 derived from agar and alginate seaweeds were fermentable by gut microbiota 466 leading to important increases in acetate and propionate.

\section{4. Conclusions}

469 All tested extracts had an influence on the composition of human gut microbiota, 470 albeit to different extents. The digested $P h$. nameko extract obtained with 471 Flavourzyme was found to hinder growth of $C$. histolyticum and growth of 472 members of the C. coccoides-E. rectale group, while growth of Bifidobacterium 473 spp. was enhanced and Lactobacillus spp. remained relatively unaffected. This 
474 selective increase in bifidobacteria coupled to a consistent increase in total SCFA

475 and lactic acid production suggest its potential prebiotic character.

476 Seaweed extracts, in particular that of O. pinnatifida obtained with Viscozyme,

477 were fermentable by gut microbiota as indicated by an increase in SCFA. 478 Increase in SCFA was not always correlated with an increase in bacterial 479 populations for the seaweed extracts.

\section{Acknowledgments}

482 This work forms part of a collaboration with the Food Microbial Sciences Unit 483 Laboratory at the University of Reading and was supported by Portuguese 484 Science Foundation (FCT - Fundação para a Ciência e Tecnologia) through 485 individual research grants references SFRH/BPD/73781/2010 and 486 SFRH/BD/77647/2011 under QREN - POPH funds, co-financed by the European 487 Social Fund and Portuguese National Funds from MCTES. Thanks are due, for 488 the financial support to CESAM (UID/AMB/50017), to FCT/MEC through national 489 funds, and the co-funding by the FEDER, within the PT2020 Partnership 490 Agreement and Compete 2020. For CBQF, this work was supported by National 491 Funds from FCT through project UID/Multi/50016/2013.

\section{References}

494 Aida, F. M. N. A., Shuhaimi, M., Yazid, M., \& Maaruf, A. G. (2009). Mushroom as a potential source of prebiotics: a review. Trends in Food Science and Technology, 20, 567-575.

497 Benus, R. F., van der Werf, T. S., Welling, G. W., Judd, P. A., Taylor, M. A., 
prausnitzii and dietary fibre in colonic fermentation in healthy human subjects. British Journal of Nutrition, 104, 693-700.

Bergillos-Meca, T., Costabile, A., Walton, G., Moreno-Montoro, M., Ruiz-Bravo, A., \& Ruiz-López, M. D. (2015). In vitro evaluation of the fermentation properties and potential probiotic activity of Lactobacillus plantarum C4 in batch culture. LWT-Food Science and Technology, 60, 420-426.

Broekaert, W. F., Courtin, C. M., Verbeke, K., Van de Wiele, T., Verstraete, W., \& Delcour, J. A. (2011). Prebiotic and other health-related effects of cerealderived arabinoxylans, arabinoxylan-oligosaccharides, and xylooligosaccharides. Critical Reviews in Food Science and Nutrition, 51, 178194.

Daims, H., Brühl, A., Amann, R., Schleifer, K. -H., \& Wagner, M. (1999). The domain specific probe EUB338 is insufficient for the detection of all bacteria: development and evaluation of a more comprehensive probe set. Systematic and Applied Microbiology, 22, 434-444.

Daims, H., Stoecker, K., \& Wagner, M. (2005). Fluorescence in situ hybridization for the detection of prokaryotes, In Molecular Microbial Ecologym Chapter 9m pp. 213. Edited by A. M. Osborn \& C. J. Smith. Abingdon, UK: Garland Science.

Devillé, C., Gharbi, M., Dandrifosse, G., \& Peulen, O. (2007). Study on the effects of laminarin, a polysaccharide from seaweed, on gut characteristics. Journal of Science of Food and Agriculture, 87, 1717-1725. 
521 Eid, N., Enani, S., Walton, G., Corona, G., Coabile, A., Gibson, G., Rowland, I., \& Spencer, J. P. E. (2014). The impact of date palm fruits and their component polyphenols, in gut microbiota ecology, bacterial metabolites and colon cancer cell proliferation. Journal of Nutritional Science, 9 pages. 10.1017/jns.2014.16

525

Franks, A. H., Harmsen, H. J. M., Raangs, G. C., Jansen, G. J., Schut, F., \& Welling, G. W. (1998). Variations of bacterial populations in human feces measured by fluorescent in situ hybridization with group-specific 16S rRNA targeted oligonucleotide probes. Applied Environmental Microbiology, 64, 3336-45.

Gibson, G. R., Scott, K. P., Rastall, R. A., \& Tuohy, K. M. (2010). Dietary prebiotics: current status and new definition. Food Science and Technological Bulletin: Functional Foods, 7, 1-19.

Gullon, B., Gullon, P., Tavaria, F., Pintado, M., Gomes, A. M., Alonso, J. L., \& Parajo, C. J. (2014). Structural features and assessment of prebiotic activity of refined arabinoxylooligosaccharides from wheat bran. Journal of Functional Foods, 6, 438-449.

Harmsen, H. J. M., Elfferich, P. Schut, F., \& Welling, G. W. (1999). A 16 S rRNAtargeted Probe for Detection of Lactobacilli and Enterococci in Faecal Samples by Fluorescent In Situ Hybridization. Microbial Ecology in Health and Disease, 3-12.

Harmsen, H. J. M., Wildeboer-Veloo, A. C. M., Grijpstra, J., Knol, J., Degener, J. E., \& Welling, G.W. (2000a). Development of $16 \mathrm{~S}$ rRNA ebased probes for the Coriobacterium group and the Atopobium cluster and their application for 
enumeration of Coriobacteriaceae in human feces from volunteers of different aged groups. Applied and Environmental Microbiology, 66, 4523-7.

Harmsen, H. J. M., Wildeboer-Veloo, A. C. M., Raangs, G. C., Wagendorp, A. A., Klijn, N., Bindels, J. G., \& Welling, B.W. (2000b). Analysis of intestinal flora development in breast-fed and formula-fed infants using molecular identification and detection methods. Journal of Pediatric Gastrenterology and Nutrition, 30, 61-7.

Langendijk, S. P., Schut, F., Jansen, J., Raangs, C. G., Kamphuis, R. G., Wilkinson, F. H. M., \& Welling, G. W. (1995). Quantitative fluorescence in situ hybridization of Bifidobacterium sp with genus-specific 16S rRNA-targeted probes and its application in fecal samples. Applied Environmental Microbiology, 61, 3069-75.

Manz, W., Amann, R. R., Ludwig, W., Vancanneyt, M., \& Schleiffer, H. K. (1996). Application of a suite of $16 \mathrm{~S}$ rRNA-specific oligo nucleotide probes designed to investigate bacteria of the phylum cytophaga-flavobacter-bacteroides in the natural environment. Microbiology, 142, 1097-1106.

Martinez, I., Kim, J., Duffy, P. R., Schlegel, V. L., \& Walter, J. (2010). Resistant starches types 2 and 4 have differential effects on the composition of the fecal microbiota in human subjects. PLoS One, 5: e15046.

Matijasic, B. B., Obermajer, T., Lipoglavsek, L., Grabnar, I., Avgustin, G., \& Rogelj, I. (2014). Association of dietary type with fecal microbiota in vegetarians and omnivores in Slovenia. European Journal of Nutrition, 53, 1051-64. 
Mills, D. J. S., Tuohy, K. M., Booth, J., Buck, M., Crabbe, M. J. C., Gibson, G. R., \& Ames, J. M. (2008). Dietary glycated protein modulates the colonic microbiota towards a more detrimental composition in ulcerative colitis patients and non-ulcerative colitis subjects. Journal of Applied Microbiology, $105,706-714$.

Pádua, D., Rocha, E., Gargiulo, D., \& Ramos, A. A., (2015). Bioactive compounds from brown seaweeds: Phloroglucinol, fucoxanthin and fucoidan as promising therapeutic agents against breast cancer. Phytochemistry Letters, 14, 91-98.

Ramnani, P., Chitarrari, R., Tuohy, K., Grant, J., Hotchkiss, S., Philp, K., Campbell, R., Gill, C., \& Rowland, I. (2012). In vitro fermentation and prebiotic potential of novel low molecular weight polysaccharides derived from agar and alginate seaweeds. Anaerobe, 18, 1-6.

Ruthes, A. C., Smiderle, F. R., \& lacomini, M. (2016). Mushroom heteropolysaccharides: A review on their sources, structure and biological effects. Carbohydrate Polymers, 136, 358-375.

Roberfroid, M., Gibson, G. R., Hoyles, L., McCartney, A. L., Rastall, R., Rowland, I., Wolvers, D., Watzl, B., Szajewska, H., Stahl, B., Guarner, F., Respondek, F., Whelan, K., Coxam, V., Davicco, M. J., Léotoing, L., Wittrant, Y., Delzenne, N. M., Cani, P. D., Neyrinck, A. M., \& Meheust, A. (2010). Prebiotic effects: metabolic and health benefits. British Journal of Nutrition, 104, S1-S63.

Rodrigues, D., Sousa, S., Silva, A. G., Amorim, M., Pereira, L., Rocha-Santos, T. A. P., Gomes, A. M. P., Duarte, A. C., \& Freitas, A. C. (2015). Impact of Enzyme- and Ultrasound-Assisted Extraction Methods on Biological 

Properties of Red, Brown, and Green Seaweeds from the Central West Coast of Portugal. Journal of Agriculture and Food Chemistry, 63, 3177-3188.

Rodrigues D, Freitas AC, Sousa S, Amorim M, Vasconcelos MW, Costa J, Silva AMS, Rocha-Santos TAP, Duarte AC, Gomes AMP. 2016. Chemical and structural characterization of Pholiota nameko extracts with biological properties. Food Chemistry, Submitted, FOODCHEM D-16-01609.

Salazar, N., Gueimonde, M., Hernández-Barranco, A. M., Ruas- Madiedo, P., \& de los Reyes-Gavilán, C. G. (2008). Exopolysaccharides produced by intestinal Bifidobacterium strains act as fermentable substrates for human intestinal bacteria. Applied and Environmental Microbiology, 74, 4737-4745.

Salazar, N., Prieto, A., Leal, J. A., Mayo, B., Bada-Gancedo, J. C., \& Madiedo, C. G. (2009). Production of exopolysacharides by Lactobacillus strains of human origin, and metabolic activity of the producing bacteria in milk. Journal of Dairy Science, 92, 52-58.

Sánchez-Patán, F., Cueva, C., Monagas, M., Walton, G. E., Gibson, G. R., Quintanilla-López, J. E., Lebrón-Aguilar, R., Martin-Álvarez, P. J., MorenoArribas, M. V., \& Bartolomé, B. (2012). In vitro fermentation of a red wine extract by human gut microbiota: Changes in microbial groups and formation of phenolic metabolites. Journal of Agricultural and Food Chemistry, 60, 21362147.

Vendrame, S., Guglielmetti, S., Riso, P., Arioli, S., Klimis-Zacas, D., \& Porrini, M. (2011). Six-week consumption of a wild blueberry powder drink increases bifidobacteria in the human gut. Journal of Agricultural and Food Chemistry, $59,12815-20$. 
615 Vulevic, J., Juric, A., Tzortzis, G., \& Gibson, G. R. (2013). A mixture of 616 transgalactooligosaccharides reduces markers of metabolic syndrome and modulates the fecal microbiota and immune function of overweight adults. Journal of Nutrition, 143, 324-31.

619

620

621

622

623

624

625

626

627

628

629

630

631

632

633

634

635

636

637

638

639

Zaporozhets. T. S., Besednova, N. N., Kuznetsova, T. A., Zvyagintseva, T. N., Makarenkova, I. D., Kryzhanovsky, S. P., \& Melnikov, V. G. (2014). The prebiotic potential of polysaccharides and extracts of seaweeds. Russian Journal of Marine Biology, 40, 1-9.

\section{Figure captions}

Figure 1. Bacterial populations (a) Bifidobacterium spp.; b) Lactobacillus spp./Enterococcus spp.; c) Bacteroides group; d) C. cocoides/E. rectale group; e) C. histolyticum group; f) Total bacteria) analysed by FISH in batch cultures containing $1 \%(\mathrm{w} / \mathrm{v})$ of digested extracts of seaweeds $\mathrm{O}$. pinnatifida obtained by Viscozyme (O.pin_Visc) and S. muticum obtained by Alcalase (S.mut_Alc) and of mushroom Ph. nameko obtained by Flavourzyme (Ph.nam_Flav) and by Cellulase (Ph.nam_Cell) and the respective controls. Error bars indicate SD of the replicates involving 3 adult donors. ${ }^{a} p<0.05$; significantly different compared to 0 h within the same substrate. " $\mathrm{p}<0.05$; significantly different compared to negative control. ${ }^{\#} \mathrm{p}<0.05$; significantly different compared to FOS, positive control.

Figure 2. Bacterial populations (a) Bifidobacterium spp.; b) Lactobacillus spp./Enterococcus spp.; c) Bacteroides group; d) C. cocoides/E. rectale group; e) C. histolyticum group; f) Total bacteria) analysed by FISH in batch cultures containing 2 and $3 \%(\mathrm{w} / \mathrm{v})$ of digested extracts of seaweed $O$. pinnatifida obtained 
640 by Viscozyme (O.pin_Visc) and of mushroom Ph. nameko obtained by 641 Flavourzyme (Ph.nam_Flav) and the respective controls. Error bars indicate SD of 642 the replicates involving 3 adult donors. ${ }^{a} p<0.05$; significantly different compared to 643 Oh within the same substrate. ${ }^{*} \mathrm{p}<0.05$; significantly different compared to negative 644 control. ${ }^{*} \mathrm{p}<0.05$; significantly different compared to $2 \%$ FOS, positive control. 